\title{
Enhancing Reactive Power Compensation with STATCOM using SVPWM
}

\author{
S.Rajendran, A.Muthu Kumar, T.Hariprasath, S.Kalimuthu Kumar, K.Vijayakumar,Rajesh,
}

\begin{abstract}
The enormous growth in the renewable energy sector has shown tremendous improvement in the energy sector which also paves the way for huge transmission traffic in transmission and distribution networks. In addition to this transmission traffic, misbehavior also happens in energy transmission and distributions. The reactive power compensation failure results in power block out. This paper provides proper solutions for compensating reactive power with help of STATCOM and its control strategies. The power quality had been improved with help of various control strategies, PWM variations, Apply Algorithm are efficient methods.
\end{abstract}

Keywords: STATCOM, SVPWM Techniques, Reactive Power.

\section{INTRODUCTION}

Power generation is an essential one for growing countries especially like as India. Power can be generated from so many resources. It may be renewable or nonrenewable one. Power cannot be generated at every place. Generated power should be transmitted to other places. During power transmission, various components are associated with it.

Associated components are operated well for smooth conduction of electrical power from one place to other place. Power system is not a static one because various environmental conditions may make impact on power system transmission and distribution networks. So its properties are strictly monitored. Electrical power is energy related quantity which can flow in power system. Power is nothing new one as a product of voltage and current instantaneously but obviously both are not synchronized in

Revised Manuscript Received on December 05, 2019.

S.Rajendran*, KARE Virudhunagar, India. rsrajendran2008@gmail.com.

A.Muthu Kumar, , KARE muthuece.eng@gmail.com

T.Hariprasath, , Kamaraj college of Engineering and Technology Virudhunagar, India, hariprasath1992@gmail.com

S.Kalimuthu KumarKARE, Virudhunagar, India. kali.12eee@ gmail.com

K.Vijayakumar, Department of electrical and electronic engineering, KARE Virudhunagar, India. kumark86@gmail.com

K.Rajesh, Department of electrical and electronic engineering, Kalasalingam Academy of Research and Education, Virudhunagar, India. k.rajesh@klu.ac.in every places. When phase difference occurs in between voltage and current, then power classified as Real (active) and reactive (apparent) power [1]-[2].

In AC system, power can be classified into Real and reactive power either producing or consuming. Real power is converting into some kind of power after its usage. Apparent power is a byproduct from power generation. Reactive power was helped lot for supporting the system to consume real power. Reactive power needed to generate electrical power with more efficient and reliable [4]-[5]. Reactive power is an imagined power which does not do any useful work. Reactive power can be freely flow back and forth in power transmission lines. The following points can make watermark the importance of reactive power. It helpful the circulating power in grid, prevent voltage collapses, empower the equipment efficiency and system reliability. Transformers, motors and transmission lines are properly working with help of reactive power.

Power systems components are designed with +5 or -5 percent voltage fluctuations. Voltage fluctuations may lead system components to malfunctioning. Because higher voltages may be cause insulation failure in system equipment's and also low voltage can make impact in performance of the components such as low illumination in lamps, over heating of coils where motors or generators used. Reactive power management skills needed to depress the voltage fluctuations. All fluctuations are works under supply and demand correlations. If power demand is over than supply then current drawn from supply is increased enormously at the same time voltage fall drastically into very low. Low voltage leads to overheating of inductive appliances and also trips the generator units. To overcome this effect, better device can be connected in the power system to operate it smoothly [9]-[11].
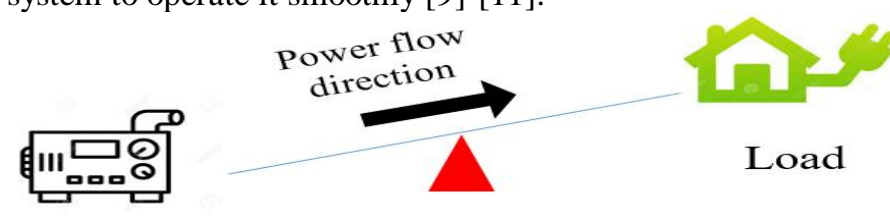

Generator

Fig.1. Real power flow without Reactive power help 


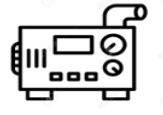

Generator

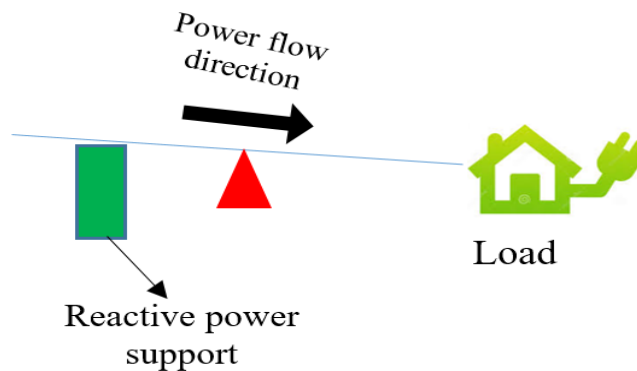

Fig. 2. Real power flow support with Reactive Power All inductive loads especially motor loads should need reactive power for converting drift electrons into valuable work. Correlation between power demand and reactive power should be properly monitored. While power demand less than the reactive power which should increase voltage level to higher value then unwanted faults/mal functioning will occur in power systems. Thus increased reactive power should be properly compensated with help of Flexible AC Transmission Systems (FACTS) devices otherwise harmful effect may arise in power system. In our world, power block outs are happened in many places. During 2012 many parts of india power system was shut down due to block out. This happened due to insufficient maintenance of reactive power in national power grids. Because many state electrical utilities are interconnected in national grids, they are properly maintained supply and demand correlation in apparent power. So ensure required reactive power should be present in long transmission lines [5].

\section{FACTS DEVICES}

In world, most of the electrical equipment's or load is either inductive or capacitive in nature. It means either apparent power may generated or consumed. Capacitive loads are injects apparent power to the transmission network and inductive loads can consumed it. Reactive power should be compensated by various methods like as use of synchronous condenser, adding of capacitor/inductor banks and FACTS devices. Capacitor or inductor banks can be adopted where reactive power should be maintained. But long distance transmission and distribution of electrical power should be properly connected with help of FACTS devices. It is nothing new one, it may use combination effect by power electronics components and inductor/capacitors.

Power system equipment's are connected nearer to receiving end so reactive power also produced nearer to the device. Suppose reactive power produced in sending end then it should travel along with other electrical properties, it leads to misbehavior. Usually reactive power can generated where is needed with help of FACTS devices. The way of connections describes the types of devices i.e. series or shunt (parallel) connected devices. The FACTS devices are series reactor, shunt reactors, STATCOM, UPFC, IQFC and synchronous condensers. Static synchronous compensator is under the family of FACTS devices. It is well-known device for generating and consuming reactive power. STATCOM is similar to other shunt devices but can provides quick responses and effective voltage control in dynamic power variation systems. Nowadays power can be generated in ' $n$ ' number of ways, as thermal, solar, geothermal, wind, bio gas and etc., Different power sources should be combined and connected with a common platform i.e. grid[10]-[11] .

\section{BLOCK DIAGRAM}

The renewable sources are becomes a major role in modern power systems. Here solar based STATCOM can be used for better understanding purposes. Here three phase sources provides power to non-linear loads, it consumed real power along with reactive power. So As per block diagram, STATCOM can be connected nearer to load. It may provide more advantages like as easy transmission, reduce transmission cost, reduce loss etc., the block diagram shows outer view of the paper. Arrow direction indicates power flow

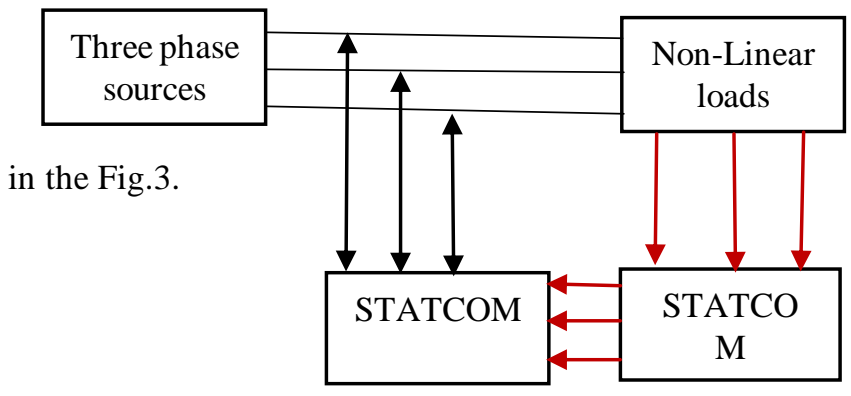

Fig. 1.3. Block diagram

This paper focused on controlling method and SVPWM based inverter for provides better solution for reactive power compensation.

\section{SVPWM}

Varieties of PWM Techniques are used for generating gate pulses an inverter. Among from various techniques, SVPWM is a sophisticated and optimum method for gate pulses that provides with low Total Harmonic Distortion(THD)[3]-[4].In SVPWM a complex reference signal generated and act as reference vector that should intents to produce remaining vectors. Here $\mathrm{Va}(\mathrm{t}), \mathrm{Vb}(\mathrm{t})$ and $\mathrm{Vc}(\mathrm{t})$ represents three phase system.

In SVPWM method Va $(\mathrm{t})=\mathrm{Vm} \sin \omega \mathrm{t}, \mathrm{Vb}(\mathrm{t})=\mathrm{Vm} \sin (\omega \mathrm{t}-2$ /3) and $\mathrm{Vc}(\mathrm{t})=\mathrm{Vm} \sin (\omega \mathrm{t}+2 / 3)$.

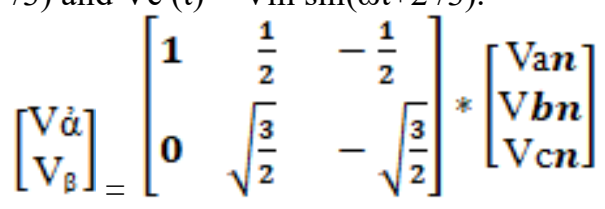

Here $\mathrm{V} \alpha$ \& V $\beta$ forms orthogonal system contains two phases. The following vector diagram describes on SVPWM. 


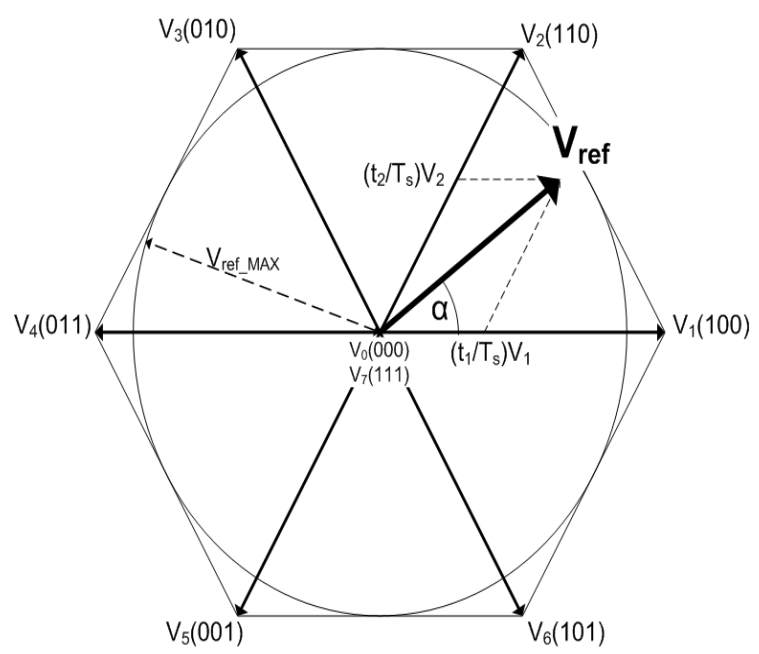

Fig. 4. SVPWM Representation

In above vector diagram figure 1.3 represents SVPWM. Where ' 0 ' negative phase voltage level \& ' 1 'positive phase voltage level.

Six Non-zero vectors starting from $V_{1}$ to $V_{6}$ makes the hexagonal shape and angle between adjacent would be 60degrees. Here $V_{0}$ and $V_{7}$ make short circuit in the output and remains in alpha beta complex plane. PWM is an ancient method for providing gate pulses. But SVPWM can generate pulses with fewer harmonic with high switching speed.

\section{SIMULATION}

The simulation diagram for SVPWM is given in figure 1.4. It provides gate pulses to the inverter. Inverter converts DC into AC. Here DC may be get it from solar or any other sources such as wind or other AC sources after that converts into DC. STATCOM is nothing but a inverter connected with Capacitor or DC link. So STATCOM controller provides instantaneous values as feedback then controller generate gate pulses according to the feedback

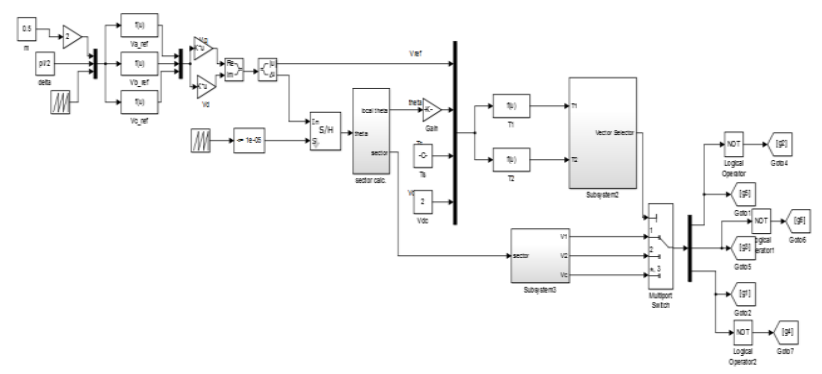

Fig.5. Simulation of SVPWM Technique

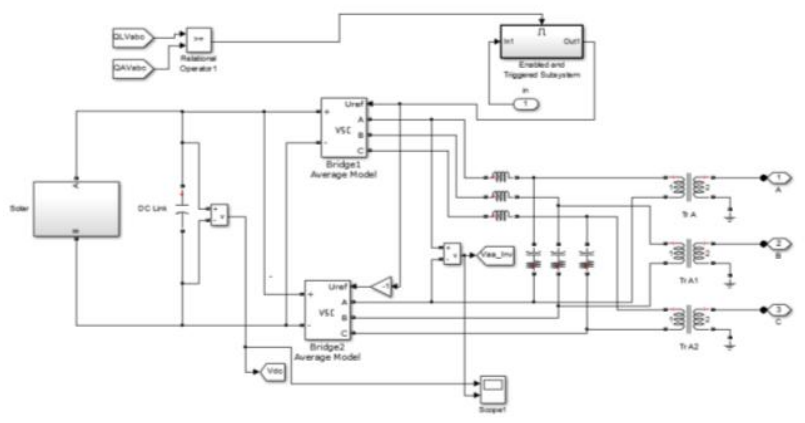

Fig. 6. STATCOM simulation with solar input
The proposed system contains Solar as DC source that power converted into AC like as inversion. DC link inductor can used for link the inverter output and loads. Two sources are connected via link inductor. Where apparent power can flow from higher magnitude to lower magnitude sources.

\section{SIMULATION OUTPUTS}

The simulation outputs are get it from MATLAB. SVPWM provides better gate pulses than other PWM methods. This gate pulses have less THD ie., Less harmonics. In this proposed SVPWM generate pulses have THD $5.36 \%$ only. It would be better with other PWM methods because SPWM may generated pulses with more than 20\% THD. Figure shows that Voltage and current waveforms after generate pulses from SVPWM.SVPWM is one of the best method to eliminate/decrease harmonics.

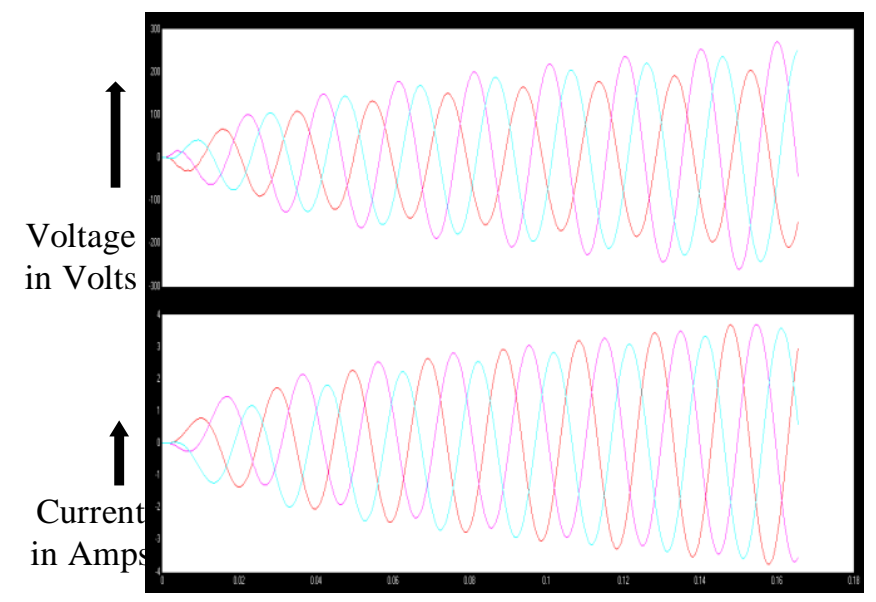

Fig.7. Simulation output results

The simulation results are discussed. This STATCOM simulation provides reactive power compensation in load side. STATCOM provide better effort to generating apparent power at near to load, it would be provide an opportunity for increasing the system efficiency and stability too. With help of STATCOM, new construction of transmission line is postponed due to its performances which enhance the transmission capabilities of the transmission lines. The resulted voltage, current waveforms are settled within a fraction of ms. Table. I show the various power values obtained from simulations.

Table-I: Real \& Reactive power table

\begin{tabular}{|l|l|l|}
\hline Place & $\begin{array}{l}\text { Real power } \\
\text { (Watts) }\end{array}$ & $\begin{array}{l}\text { Reactive } \\
\text { power (VAr) }\end{array}$ \\
\hline Source side & 1000 & 3.8 \\
\hline Load side & 702.6 & 308.6 \\
\hline STATCOM side & 289.8 & 310.5 \\
\hline
\end{tabular}

The hardware setup is ongoing for STATCOM setup with help of

Published By:

Blue Eyes Intelligence Engineering 
Intelligent Power Module (IPM). IPM has in-built gate driver circuit and also combined over voltage \& over current protection circuits.

\section{CONCLUSION}

This paper provides simulated solution for reactive power compensation with help of STATCOM. The efficiency is increased while pulses are generated with help of SVPWM method. The resulted waveform clearly shows about the stability of voltage and current. The resulted values are tabulated. The proposed system provides better solution for reactive power related problems occurred in home, industries or electricity board. This would be grateful in transmission and distribution for maintaining higher power factor approximately unity power factor.

\section{REFERENCES}

1. Pranesh Rao, M. L. Crow, and ZhipingYang, "STATCOM Control for Power System Voltage Control Applications". IEEE Transactions on Power Delivery, vol. 15, no. 4, Oct 2000.

2. Naveen Goel, R.N. Patel, Member, IEEE, Saji T. Chacko,"Genetically Tuned STATCOM for Voltage Control and Reactive Power Compensation". International Journal of Computer Theory and Engineering, vol. 2, no. 3, June, 2010.

3. Zhenyu Yu, Arefeen Mohammed, IssaPanahi. 1997. A Review of Three PWM Techniques. Proceedings of the American Control Conference Albuquerque, New Mexico. pp. 257-261.

4. Raed H. Ahmad, George G. Karady, Tracy D. Blake, Peter Pinewski. Comparison of Space Vector Modulation Techniques based on performance Indexes and Hardware Implementation. Electrical Engg. Department, Arizona State University.

5. S.Rabik raja, S.Rajendran and S.Kannan "d-q control based STATCOM reactive power compensation", Accepted for presentation International Conference on Circuits, Power and Computing Technologies (ICCPCT-2015), Noorul Islam Centre for Higher Education, Kumaracoil to be held on 19-20 March, 2015.

6. B. S. Chen and Y. Y. Hsu, "An analytical approach to harmonic analysis and controller design of a STATCOM," IEEE Trans. Power Del., vol. 22, no. 1, pp. 423-432, Jan. 2007

7. M.Prabhu, J,Kohila, S.Rajendran and S.Kannan, "Implementation of SHE In Solar Energy Conversion System", 2014 IEEE International Conference on Advanced Communication Control and Computing Technologies (ICACCCT) held at Syed Ammal College of Engg May 8th to 10th,2014.

8. A. Arulampalam, M. Barnes, N. Jenkins, and J. Ekanayake, "Power quality and stability improvement of a wind farm using STATCOMsup-ported with hybrid battery energy storage,",vol. 153, pp. 701-710, Nov. 2006.

9. Gerardo Escobar Valderrama, Paolo Mattavelli, and Aleksand r M. Stankovi ', "Reactive Power and Unbalance Compensation Using "STATCOM with Dissipativity-Based Control" IEEE Transactions on Control Systems Technology, vol. 9, no. 5, Sept 2001.

10. Pranesh Rao, M. L. Crow, and Zhiping Yang, "STATCOM Control for Power System voltage Control Applications". IEEE Transactions on Power Delivery, vol. 15, no. 4, Oct 2000.

11. NaveenGoel, R.N.Patel,Member, IEEE,SajiT.Chko,"Genetically Tuned STATCOM for Voltage Control and Reactive Power Compensation". International Journal of Computer Theory and Engineering, vol.2, no.3 June, 2010.

\section{AUTHORS PROFILE}

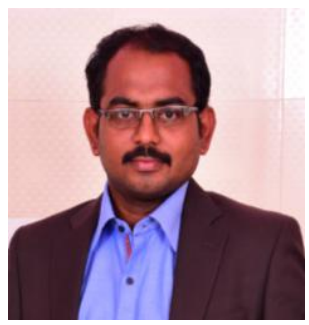

S.Rajendran received his UG degree in Electrical Engineering from Anna University, Chennai with First Class Distinction in 2009 and M.E. degree in Power Electronics and Drives from Anna University, Tiruchirappalli with First Class Distinction in 2011. Now He was pursuing $\mathrm{Ph} . \mathrm{D}$ in the field of reactive power compensation. Since July 2011, he has been working as an Assistant Professor in the Department of Electrical \& Electronics Engineering, Kalasalingam Academy of Research and Education, Krishnankoil, Virudhunagar District, Tamil Nadu and India. He has attended several international conferences and he has been actively involving himself in research since 2015. His current research interests include reactive power compensation in FACTS devices. He has actively participated in various faculty development programs, symposiums, orientation programs, workshops and national seminars. He has received Teaching Competency Award in the year 2017. He completed CLAD (Certified Lab view Associate Developer) in 2018.

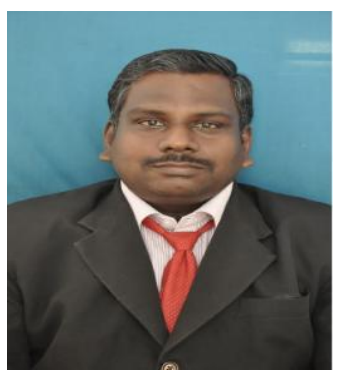

Dr. Muthukumar Arunachalam completed B.E. in Electronics and Communication Engineering from PSYEC Madurai Kamaraj University with First Class Distinction in 2004. Following that, he completed M.E. in Applied Electronics from MSEC, Anna University and Ph.D. from Kalasalingamuniversity in 2006 and 2014 respectively. Currently, he is working as associate professor in Electronics and Communication Engineering department, Kalasalingam University, India, where he has been working since 2007. He has more than 12 years of teaching experience in academic. His area of interest is Image processing, signal processing, biometrics and wireless communication. He is a life member of ISTE, IAENG. He has successfully guided $4 \mathrm{M}$.Tech and 33 batch B.Tech students. Currently he is guiding 5 Ph.D scholars. He has published 12 papers in International Journals and presented 43 papers in conferences. He is actively involved in the NBA (National Board of Accreditation), NAAC (National Assessment and Accreditation Council), member of BoS (Board of Studies) and Academic Council of Kalasalingam University. He is recognized as Doctoral Committee member for 4 research scholars in Anna University, Chennai. He is the reviewer in international journals like, Biomedical Signal Processing \& Control (Elsevier Journal), Biometrics (IET Journal), The International Journal of Computer Aided Engineering and Technology (Inder science Journal), IEEE Transactions on Systems, Man and Cybernetics: Systems(IEEE Journal) and Bentham journal.

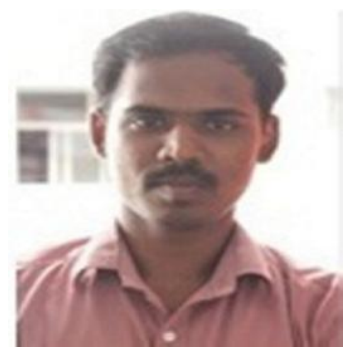

T.Hari Prasath received his UG degree in Electrical and Electronics Engineering in Mepco Schlenk Engineering College, Sivakasi with First Class Distinction in 2013 and M.E. degree in Industrial Safety Engineering from Mepco Schlenk Engineering College, Sivakasi, India, in 2015.. Now he was working as Assistan Professor in Kamaraj College of Engineering and Technology, Virudhunagar. He was published 6 papers in international journals and actively participated in various faculty development programs, symposiums, orientation programs, workshops and national seminars. Formerly, he was worked in Larson \& Toubro as Environment Health and Safety (EHS) Officer. He was honored with Best outgoing student in the year 2015 in Mepco Schlenk Engineering College, Sivakasi.

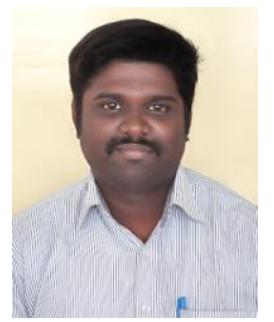

S.Kalimuthu Kumar received his UG degree in Electrical and Electronics Engineering from Anna University, Chennai in 2008 and M.Tech. Degree in Embedded System technology from kalasalingam University, Krishnankoil, in 2011. Since July 2011 he has been working as an Assistant Professor in the Department of Electrical \& Electronics Engineering, Kalasalingam University, Krishnankoil, Virudhunagar District, Tamil Nadu and India. He published 6 papers in international conferences and journals. He has attended several international conferences and he has been actively involving himself in research since 2014 . He has actively participated in various faculty development programs, symposiums, orientation programs, workshops and national seminars. He completed CLAD (Certified Lab view Associate Developer) in 2018. 


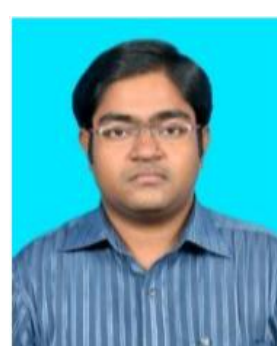

K.Vijaya Kumar received his UG degree in Electrical and Electronics Engineering from Easwari Engineering college, Anna University, Chennai in 2009 and M.E. degree in Power Electronics and Drives from Mepco Schlenk Engineering College, Anna University, Tirunelveli, in 2011. He completed (Distance mode) Master of Business Administration (MBA) from SRM University in 2016. Since July 2011, he has been working as an Assistant Professor in the Department of Electrical \& Electronics Engineering, Kalasalingam University, Krishnankoil, Virudhunagar District, Tamil Nadu and India. He has attended several international conferences and he has been actively involving himself in research since 2012. He published 10 papers in various international conferences, international journals and magazines. His current research interests include Matrix converters, reactive power compensation and optimization techniques in various applications. He has actively participated in various faculty development programs, symposiums, orientation programs, workshops and national seminars. He was working as Business Consultant to Minniyal Private Limited, Start-up Organization initiated under the financial support of National Science \& Technology Entrepreneurship Development Board, DST, Govt. of India, New Delhi. He completed CLAD (Certified Lab view Associate Developer) in 2018.

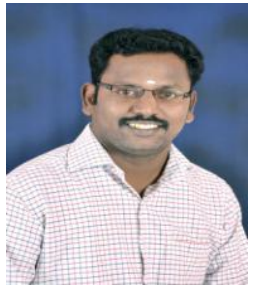

K. Rajesh was born in Rajapalayam, Tamil Nadu, India, in May 1987. He received his UG degree in Electrical Engineering from Anna University, Chennai in 2008 and M.E. degree in Power Systems Engineering from Anna University, Tirunelveli, Tamil Nadu, India, in 2011. Since July 2011, he has been working as an Assistant Professor in the Department of Electrical \& Electronics Engineering, Kalasalingam University, Krishnankoil, Virudhunagar District,

Tamil Nadu and India.

He has attended several international conferences and he has been actively involving himself in research since 2013. Three of his research papers have been published in international journals and a research paper has been published in national journal. His current research interests include generation expansion planning, energy planning, power system optimization and power system control. He has actively participated in various faculty development programs, symposiums, orientation programs, workshops and national seminars. He has received Teaching Competency Award in the year 2015 and Research Competency Award in the year 2015 \& 2017. He is a Lifemember of ISTE and Member of IE(I). 